Cite this: J. Anal. At. Spectrom., 2014, 29, 1339

\title{
Slicing - a new method for non destructive 3D elemental sensitive characterization of materials $\uparrow$
}

Received 28th February 2014

Martin Radtke, ${ }^{\text {*a }}$ Günter Buzanich, ${ }^{a}$ Jessica Curado, ${ }^{a}$ Uwe Reinholz, ${ }^{a}$ Heinrich Riesemeier ${ }^{a}$ and Oliver Scharf ${ }^{b}$

Accepted 7th April 2014

DOI: $10.1039 / c 4 j a 00085 d$

www.rsc.org/jaas

Recent advances in synchrotron sources and detector technology have led to substantial improvements in spatial resolution and detection limits for X-ray fluorescence analysis (XRF). However, the non-destructive three-dimensional elemental sensitive characterization of samples remains a challenge. We demonstrate the use of the so-called "Color X-ray Camera" (CXC) for 3D measurements for the first time. The excitation of the sample is realized with a thin sheetbeam. The stepwise movement of the sample allows getting the elemental distribution for each layer with one measurement. These layers can be combined to a full 3D dataset for each element afterwards. Since the information is collected layer by layer, there is no need to apply reconstruction techniques, which quite often are the reason for artifacts in the results achieved by computed tomography (CT). The field of applications is wide, as the 3D elemental distribution of a material contains clues to processes inside the samples from a variety of origins. The technique is of special interest and well suited for biological specimens, because their light matrix minimizes restricting absorption effects. Measurement examples of a hornet and the teeth of a Sorex araneus are shown.

\section{Introduction}

The determination of the non-destructive three-dimensional distribution of elements with X-ray fluorescence (XRF) in a sample can provide valuable insights into the function and composition of the analyzed materials. ${ }^{\mathbf{1 - 6}}$ Methods used to get this information today are based on confocal setups or computed tomography., ${ }^{3,6}$ These techniques have significant drawbacks regarding the number of individual measurements, sample geometry and the necessity of reconstruction. We report

${ }^{a} B A M$ Federal Institute for Materials Research and Testing, Richard-Willstätter-Strasse 11, 12489 Berlin, Germany. E-mail: martin.radtke@bam.de

${ }^{b}$ IfG Institute for Scientific Instruments GmbH, Rudower Chaussee 29/31, 12489 Berlin, Germany

$\dagger$ Electronic supplementary information (ESI) available: See DOI: 10.1039/c4ja00085d a new 3D technique which overcomes these disadvantages. The technique is based on an energy dispersive high-frame-rate, lownoise X-ray pn-CCD ${ }^{7,8}$ chip with capillary X-ray optics, the socalled "Color X-ray Camera" (CXC), ${ }^{9-12}$ using a sheet beam. The chip was developed originally for space missions and afterwards it has been adapted for free electron laser (FEL) applications. ${ }^{\mathbf{1 3 - 1 5}}$ The CXC has 70000 pixels and each is an energy dispersive detector. Therefore, the $2 \mathrm{D}$ elemental distribution is measured simultaneously and not consecutively by scanning. The presented technique is the X-ray equivalent to scanned light sheet microscopy presented by Keller et al. $2008 .^{16}$ Instead of the term "X-ray sheet microscopy" we suggest the more concise term "slicing" in analogy to multi-slice computed tomography. ${ }^{17}$

\section{Experimental methods}

The basic idea for this new method is quite simple. As shown in Fig. 1, we use a beam for excitation with restricted vertical or horizontal beam size parallel to the detector surface. In this dimension, the achievable resolution is defined by the beam
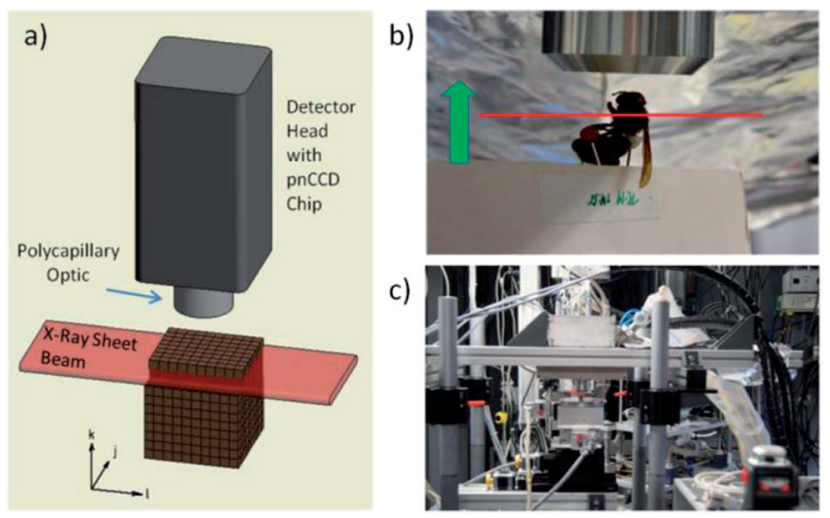

Fig. 1 (a) The geometry for slicing measurements. (b) The sample is moved stepwise in direction $\vec{k}$ and the data are recorded layer per layer. (c) Photograph of the set-up at the BAMline. 
size. An advantage of the method is that all geometric parameters are well defined from the set-up. While the layer height is given from the height of the incoming parallel X-ray sheet beam, the depth inside the sample is given simply from the sample movement. Normally the step size is equal to the height of the beam, therefore the depth of a particular layer can be calculated by the layer number times step size.

At the BAMline ${ }^{18}$ we tested two different geometries. First, we positioned the camera sidewards, to preserve the traditional $90^{\circ}$ geometry for XRF where the scattered signal is minimized. In this way, due to the layout of the BAMline and the properties of the synchrotron radiation, it is not possible to achieve the desired beam size with optimal flux on the sample and therefore the measurements suffered from low count rates. To overcome this problem, we positioned the camera horizontal looking down on the sample. In this geometry we can bend the second multilayer of the double multilayer monochromator (DMM) to focus and generate an excitation beam of $50 \mu \mathrm{m}$ height. The DMM can be used as a mirror or in Bragg geometry to provide an intense "white" or a monochromatic beam. Of course, in this geometry we measure a much higher scattering signal, but what seemed a disadvantage at first, turned out to be very useful, since the signal of the scattered radiation reproduces the sample geometry with high precision. Additionally, the ratio of elastic to inelastic scattering is an indicator for the average atomic number of the "dark matrix", especially useful for biological samples which consist mainly of light elements.

The other two dimensions are dependent on the optic which is used to generate the image in the camera. In the presented example, we use straight polycapillary optics offering a lateral resolution of $(48 \times 48) \mu \mathrm{m}^{2}$. First tests with magnifying optics and a resolution of $(8 \times 8) \mu \mathrm{m}^{2}$ worked excellent. However, the better resolution is paid for with lower detection efficiency and therefore prolonged measuring times. Furthermore a beam height of $8 \mu \mathrm{m}$ with sufficient flux can currently not be reached at the BAMline. These drawbacks will be eliminated in the future by the use of an X-ray optic to increase the primary flux density and a coded aperture to enhance the detection efficiency by an order of magnitude or more..$^{19,20}$

\section{Data treatment}

As mentioned before, there is no need for reconstruction. Anyhow, the raw data must be processed to extract the desired information. Data processing is done in the following steps:

- Count rates are normalized for each layer.

- The sum spectrum and so-called "max spectrum" are calculated to identify existing elements.

- Regions of interest (ROIs) are defined for each element and for the scattering signal.

- Counts are extracted for each ROI in each spectrum.

- For each element the three-dimensional data cube is created.

- Visualization of the results.

The normalization is necessary to compensate variations in the intensity of the excitation beam over time. It is done by selecting a part of the layer $k$ where there is no signal of the object under investigation. The normalization factor $N_{k}$ is the sum of the scattering signal from the air in this area.

$$
N_{k}=\sum_{l=l_{0}}^{l_{1}} \sum_{j=j_{0}}^{j_{1}} \sum_{i=i_{0}}^{i_{1}} y_{i, j, k, l}
$$

where $k$ denotes the layer and $l$ and $j$ are the indices of the pnCCD pixel for spectrum $y$. The scattered signal in the spectra is summed from channel $i_{0}$ to $i_{1}$ within the area defined by the start point $\left(l_{0}, j_{0}\right)$ and the end point $\left(l_{1}, j_{1}\right)$. The sum spectrum is obtained by simply adding all spectra. The disadvantage thereby is, that peaks for elements which are present only in a few pixels, are likely to cease in the background. The "max spectrum" $y_{\max }$ is therefore constructed in a way, that for each channel $i$ only the maximum value out of all spectra is taken into account.

$$
y_{\max }(i)=\max (y(j, k, l, i))
$$

This simplifies the identification of elements which are present only in a few pixels.

From the sum and the max spectra the ROIs for the elements of interest are defined. This is done by determining first automatically the position of the maximum of all fluorescence and scattering peaks in the sum spectra. These are the centers of the ROIs. The widths of the ROIs are influenced by the energy resolution of the detector and are set to 8 channels (approximately $160 \mathrm{eV}$ ). The max spectrum serves for control purposes to make sure no minor peaks have been overlooked. The assignment from ROIs to elements is done manually. To avoid artifacts, it is important to check for peak overlaps and select suitable ROIs for imaging. Since the pixel spectra are practically background free no treatment regarding background subtraction is necessary.

We can now for each element construct a three-dimensional data cube which contains the distribution to be visualized in standard software like imageJ or IDL (Interactive Data Language).

In strong absorbing materials an additional correction may be necessary, which due to the simple geometry can be done in a straightforward manner. The measured volume is divided and can be corrected for absorption voxel by voxel. For an arbitrary voxel $V_{j k l}$ (with the fixed coordinate $l=n$ ) the excitation beam must pass through the sample and the absorption $A^{\text {exc }}$ is given as the product of the absorption $a$ in the traversed voxels:

$$
A_{j k(l=n)}^{\mathrm{exc}}=\left(1-a_{j k(l=n-1)}\right)\left(1-a_{j k(l=n-2)}\right) \ldots\left(1-a_{j k(l=n-n)}\right)
$$

The fluorescence and scattered signals pass through the voxels between the voxel of interest $V_{j k l}$ (with the fixed coordinate $k=n$ ) and the detector. The absorption $A^{\text {fs }}$ can be calculated similar to the excitation from the product:

$$
A_{j(k=n) l}^{\mathrm{fs}}=\left(1-a_{j(k=n-1) l}\right)\left(1-a_{j(k=n-2) l}\right) \ldots\left(1-a_{j(k=n-n) l}\right)
$$

As absorption is energy dependent, the factor $A^{\mathrm{fs}}$ must be calculated for each fluorescence line separately. A problem 
arises, if the absorption $a_{j k l}$ in each voxel is not known prior to the analysis. This is particularly the case in finely structured biological samples like insects. For a good approximation it is possible to calculate the effective atomic number and the density for each voxel from the Rayleigh to Compton scattering ratio. ${ }^{21-23}$

Assuming that the absorption in air can be neglected and calculating in the right order, this means from the top to the bottom of the sample and from the entrance to the exit side of the beam, these calculations can be made in a non-iterative scheme, where all necessary data are known in each step. Of course, this gives only reasonable results, if the original signal is still present in the measurement and not completely absorbed. This problem arises especially, if a light element is below a heavier element and the fluorescence signal is absorbed with high efficiency. To this respect, slicing has the same restrictions as X-ray fluorescence tomography or confocal measurements. Anyhow, at the moment the technique is intended to give qualitative results only and therefore correction is not mandatory and absorption can be identified by visual inspection inside the images.

\section{Applications}

To illustrate the power of this new method the results of measurements taken at the BAMline are presented here. The first examined object was the preparation of a hornet. The distribution and the content of trace elements in insects are of increasing interest because of three aspects. First of all, it gives the biologists insights into the organization and function of the

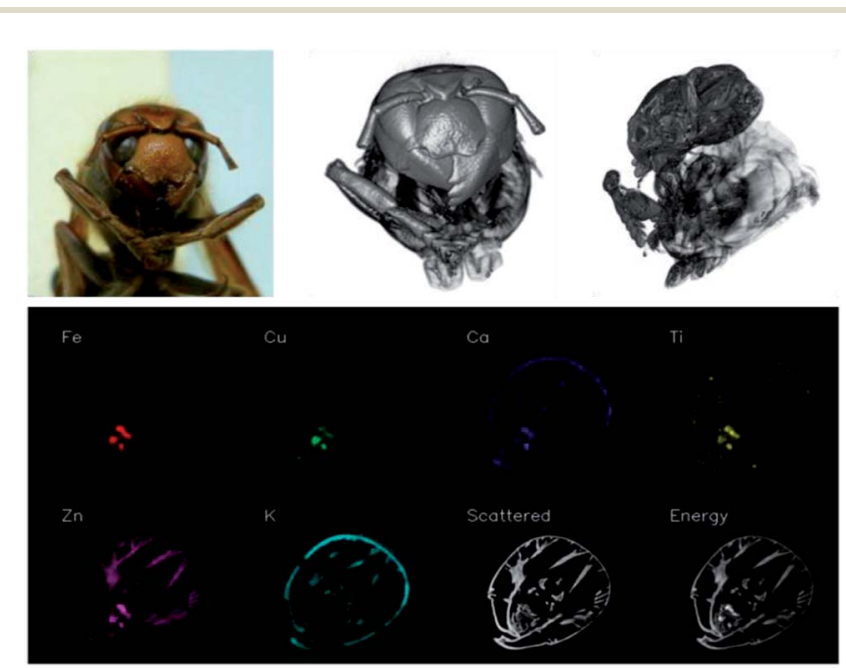

Fig. 2 At the top a picture of the examined hornet, the reconstruction of the surface and a look inside the sample from the scatter signal. Below the distribution of elements in the $53^{\text {rd }}$ layer with a resolution of $(50 \times 50) \mu \mathrm{m}^{2}$. Additionally the scattered intensity and the total deposited energy per pixel are shown. The deposited energy is equivalent to the measurement with a conventional CCD without energy resolution. An animation of the three dimensional distributions can be found in the ESI $\uparrow .200$ layers with a recording time of 7 minutes per layer, corresponding to about $6 \mathrm{~ms}$ per voxel, were measured (total measurement time of about $24 \mathrm{~h}$ ). organism. ${ }^{24}$ Second, the uptake of metals from food and water sources by insects is thought to be additive. Insects have therefore a large potential as biomonitors of metal contamination in nature. ${ }^{25}$ At last, insects are expected to gain increasing importance in the feed and food market as replacers for animal-derived proteins as novel protein sources. ${ }^{\mathbf{2 6}}$

The hornet was chosen, because its physical dimensions fit perfectly to the spatial resolution of the experimental set-up. The measured distribution of various elements as well as the scattered signal is shown in Fig. 2. Here the benefit of the scattered signal to visualize the sample is clearly visible. The look inside the sample demonstrates that it is possible to distinguish different regions of the sample through the intensity of the scattered signal. This is in analogy to regions with different densities which can be determined by computed tomography, but with our technique we get additionally the information of the positions of the elements. In Fig. 3 the sum and the max spectra are shown. The good energy resolution of the pn-CCD allows for the identification of various elements. In this case the distribution of iron, copper, calcium, potassium, titanium and zinc was detectable and as mentioned before, the scattered radiation allowed a detailed reconstruction of the morphology.

The use of a magnifying capillary optic is illustrated in Fig. 4. In this case iron and calcium were detected in the enamel of a common shrew, Sorex araneus (Soricidae, Lipotyphla). It is known, that the enamel of a variety of vertebrate taxa (e.g. teleosts, amphibians, and mammals) contains iron on or below the tooth's surface. ${ }^{27}$ In all but the outermost layer, red enamel containing iron is harder than the white enamel found in white toothed shrews (Crocidurinae). This is related to enhanced wear-resistance of areas exposed to increased stress. In mammals, red enamel containing iron is found in rodents and red toothed shrews (Soricinae), where it occurs on dental cusps and shearing surfaces. These findings have been confirmed with this new non-invasive approach in mapping of iron and calcium.

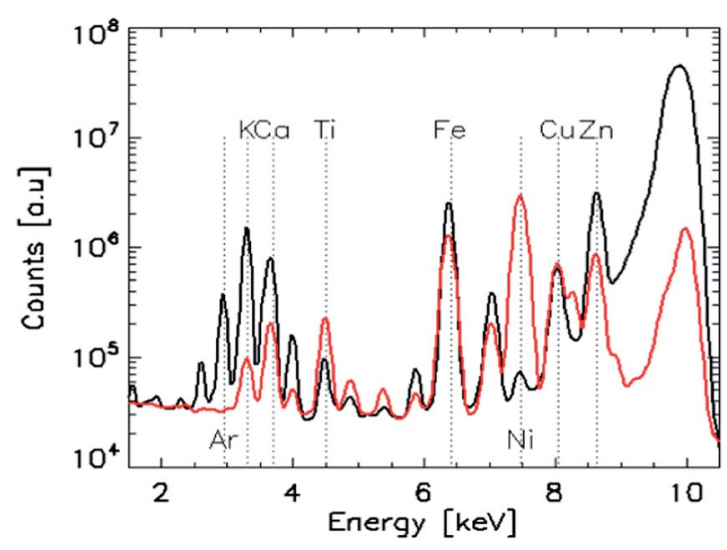

Fig. 3 The sum (black) and the max (red) spectra of the hornet measurement. The elements are distributed fairly equal and therefore the elements which can be identified are nearly identical in both spectra. An exception is Ar, which is present in air and therefore only visible in the sum spectrum. Ni appears much more prominent in the max spectrum, which means, that it is concentrated in a hot spot. 

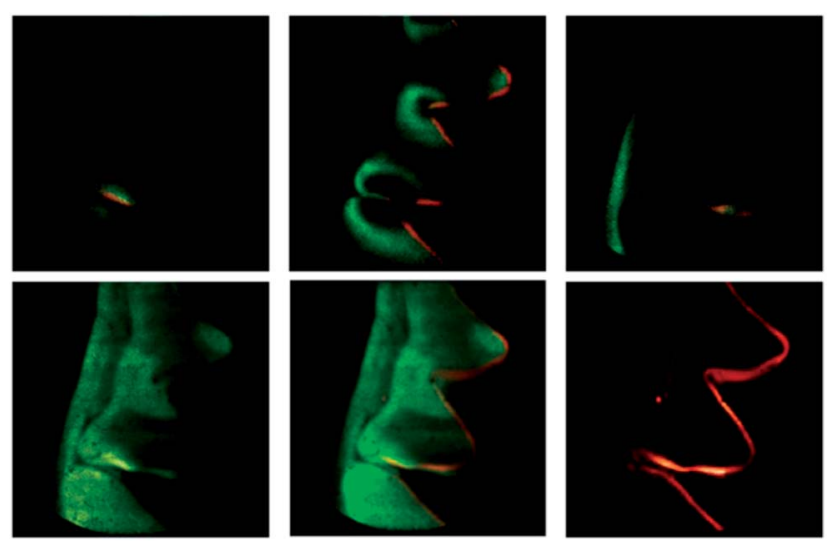

Fig. 4 The elemental distribution of $\mathrm{Ca}$ (green) and $\mathrm{Fe}$ (red) in the teeth of a common shrew, Sorex araneus is shown. In the upper row slices from the top, the middle and the bottom layer of our measurements are displayed. The absorption effect is clearly visible. The bottom row illustrates the distribution of the elements for the whole measurement. The resolution in depth for this dataset is 100 $\mu \mathrm{m}$, in the image plane the pixel size is $(8 \times 8) \mu \mathrm{m}^{2} .32$ layers with a total measuring time of $16 \mathrm{~h}$ were measured. This is equal to a measurement time of 30 minutes per layer or 25 ms per voxel.

\section{Discussion and conclusions}

The presented examples illustrate the power of the new slicing method. The main characteristic is that the elemental distribution for each layer is achieved with one measurement. The depth resolution depends on the geometry of the excitation beam while the lateral resolution depends on the used optics. The sample size is not restricted, as different measurements can be combined. Anyhow, the volume which can be probed is restricted by the absorption of the excitation beam and the fluorescence signal in the sample. In comparison with computed tomography there are various advantages. First, there is no need for reconstruction and therefore there are no artifacts. Second, while CT is only sensitive to density variations, we detect chemical elements. This can be achieved by $\mathrm{X}$ ray fluorescence tomography as well, but there again a reconstruction is necessary. At last, slicing has much less restrictions for sample geometry. It is not necessary that the exciting beam should traverse the whole sample since the absorption in the hind part of the sample does not influence the measurements of the front part.

Even though slicing and measurements in confocal geometry are very similar, the latter is unfavorable in two aspects. On one hand, each voxel has to be measured separately which means that 70000 single measurements are necessary to obtain the information of one slice. Collecting a full 3D dataset like in our example of the hornet cannot be done in a reasonable time. In practice this technique is restricted to the measurement of depth profiles. Examples, where real 3-D measurements have been performed with a confocal setup are unusual and reserved for exceptional samples, like rare diamonds ${ }^{28}$ or the investigation of important medical issues. ${ }^{29}$ The second disadvantage of confocal measurements is, that absorption corrections are in general more difficult due to the non-orthogonal geometry. ${ }^{30}$
Using the slicing technique opens a wide field of applications, since the 3D elemental distribution of a material contains clues to processes taking place inside the samples from a variety of origins. The technique is of special interest and well suited for biological specimens, because the light matrix minimizes restricting absorption effects. Another field of application is e.g. archaeometry due to the non-destructive nature of the method.

The next step will be, to produce quantitative data, but due to the number of spectra, a completely new evaluation method must be developed. In the future, using a similar setup, modern, high brilliant X-ray sources will allow for improvement of the depth resolution down to the nanometer scale. ${ }^{31}$ The spatial resolution will be enhanced by new optics and detectors with higher performance. Aiming for a better resolution implies that we have to use smaller samples, which has the positive side effect that the problem of absorption effects in the sample diminishes. In the future it will be possible to examine single cells with this technique.

\section{Author contributions}

The manuscript was written through contributions of all authors. All authors have given their approval to the final version of the manuscript.

\section{Acknowledgements}

The authors like to acknowledge Peter Giere and Frieder Mayer from the Museum für Naturkunde, Leibniz Institute for Research on Evolution and Biodiversity at the Humboldt University Berlin, Germany, for the Sorex araneus (ZMB_MAM_61372) sample.

\section{References}

1 B. Borah, G. J. Gross, T. E. Dufresne, T. S. Smith, M. D. Cockman, P. A. Chmielewski, M. W. Lundy, J. R. Hartke and E. W. Sod, Anat. Rec., 2001, 265, 101-110.

2 B. Kanngiesser, W. Malzer and I. Reiche, Nucl. Instrum. Methods Phys. Res., Sect. B, 2003, 211, 259-264.

3 P. Ruegsegger, B. Koller and R. Muller, Calcif. Tissue Int., 1996, 58, 24-29.

4 L. Salvo, P. Cloetens, E. Maire, S. Zabler, J. J. Blandin, J. Y. Buffiere, W. Ludwig, E. Boller, D. Bellet and C. Josserond, Nucl. Instrum. Methods Phys. Res., Sect. B, 2003, 200, 273-286.

5 D. Ulrich, B. Van Rietbergen, A. Laib and P. Ruegsegger, Bone, 1999, 25, 55-60.

6 L. Vincze, B. Vekemans, F. E. Brenker, G. Falkenberg, K. Rickers, A. Somogyi, M. Kersten and F. Adams, Anal. Chem., 2004, 76, 6786-6791.

7 L. Strüder, H. Brauninger, M. Meier, P. Predehl, C. Reppin, M. Sterzik, J. Trumper, P. Cattaneo, D. Hauff, G. Lutz, K. F. Schuster, A. Schwarz, E. Kenziorra, A. Staubert, E. Gatti, A. Longoni, M. Sampietro, V. Radeka, P. Rehak, S. Rescia, P. F. Manfredi, W. Buttler, P. Holl, J. Kemmer, 
U. Prechtel and T. Ziemann, Nucl. Instrum. Methods Phys. Res., Sect. A, 1990, 288, 227-235.

8 L. Strueder, S. Eppa, D. Rolles, R. Hartmann, P. Holl, G. Lutz, H. Soltau, R. Eckart, C. Reich, K. Heinzinger, C. Thamm, A. Rudenko, F. Krasniqi, K.-U. Kuehnel, C. Bauer, C.-D. Schroeter, R. Moshammer, S. Techert, D. Miessner, M. Porro, O. Haelker, N. Meidinger, N. Kimmel, R. Andritschke, F. Schopper, G. Weidenspointner, A. Ziegler, D. Pietschner, S. Herrmann, U. Pietsch, A. Walenta, W. Leitenberger, C. Bostedt, T. Moeller, D. Rupp, M. Adolph, H. Graafsma, H. Hirsemann, K. Gaertner, R. Richter, L. Foucar, R. L. Shoeman, I. Schlichting and J. Ullrich, Nucl. Instrum. Methods Phys. Res., Sect. A, 2010, 614, 483-496.

9 I. Reiche, K. Muller, M. Alberic, O. Scharf, A. Waehning, A. Bjeoumikhov, M. Radtke and R. Simon, Anal. Chem., 2013, 85, 5857-5866.

10 A. Kühn, O. Scharf, I. Ordavo, H. Riesemeier, U. Reinholz, M. Radtke, A. Berger, M. Ostermann and U. Panne, J. Anal. At. Spectrom., 2011, 26, 1986-1989.

11 I. Ordavo, S. Ihle, V. Arkadiev, O. Scharf, H. Soltau, A. Bjeoumikhov, S. Bjeoumikhova, G. Buzanich, R. Gubzhokov, A. Guenther, R. Hartmann, P. Holl, N. Kimmel, M. Kuehbacher, M. Lang, N. Langhoff, A. Liebel, M. Radtke, U. Reinholz, H. Riesemeier, G. Schaller, F. Schopper, L. Strueder, C. Thamm and R. Wedell, Nucl. Instrum. Methods Phys. Res., Sect. A, 2011, 654, 250-257.

12 O. Scharf, S. Ihle, I. Ordavo, V. Arkadiev, A. Bjeoumikhov, S. Bjeoumikhova, G. Buzanich, R. Gubzhokov, A. Guenther, R. Hartmann, M. Kuehbacher, M. Lang, N. Langhoff, A. Liebel, M. Radtke, U. Reinholz, H. Riesemeier, H. Soltau, L. Strueder, A. F. Thuenemann and R. Wedell, Anal. Chem., 2011, 83, 2532-2538.

13 H. N. Chapman, P. Fromme, A. Barty, T. A. White, R. A. Kirian, A. Aquila, M. S. Hunter, J. Schulz, D. P. DePonte, U. Weierstall, R. B. Doak, F. R. N. C. Maia, A. V. Martin, I. Schlichting, L. Lomb, N. Coppola, R. L. Shoeman, S. W. Epp, R. Hartmann, D. Rolles, A. Rudenko, L. Foucar, N. Kimmel, G. Weidenspointner, P. Holl, M. Liang, M. Barthelmess, C. Caleman, S. Boutet, M. J. Bogan, J. Krzywinski, C. Bostedt, S. Bajt, L. Gumprecht, B. Rudek, B. Erk, C. Schmidt, A. Hoemke, C. Reich, D. Pietschner, L. Strueder, G. Hauser, H. Gorke, J. Ullrich, S. Herrmann, G. Schaller, F. Schopper, H. Soltau, K.-U. Kuehnel, M. Messerschmidt, J. D. Bozek, S. P. HauRiege, M. Frank, C. Y. Hampton, R. G. Sierra, D. Starodub, G. J. Williams, J. Hajdu, N. Timneanu, M. M. Seibert, J. Andreasson, A. Rocker, O. Joensson, M. Svenda, S. Stern, K. Nass, R. Andritschke, C.-D. Schroeter, F. Krasniqi, M. Bott, K. E. Schmidt, X. Wang, I. Grotjohann, J. M. Holton, T. R. M. Barends, R. Neutze, S. Marchesini, R. Fromme, S. Schorb, D. Rupp, M. Adolph, T. Gorkhover, I. Andersson, H. Hirsemann, G. Potdevin, H. Graafsma, B. Nilsson and J. C. H. Spence, Nature, 2011, 470, 73-U81.

14 M. M. Seibert, T. Ekeberg, F. R. N. C. Maia, M. Svenda, J. Andreasson, O. Joensson, D. Odic, B. Iwan, A. Rocker,
D. Westphal, M. Hantke, D. P. DePonte, A. Barty, J. Schulz, L. Gumprecht, N. Coppola, A. Aquila, M. Liang, T. A. White, A. Martin, C. Caleman, S. Stern, C. Abergel, V. Seltzer, J.-M. Claverie, C. Bostedt, J. D. Bozek, S. Boutet, A. A. Miahnahri, M. Messerschmidt, J. Krzywinski, G. Williams, K. O. Hodgson, M. J. Bogan, C. Y. Hampton, R. G. Sierra, D. Starodub, I. Andersson, S. Bajt, M. Barthelmess, J. C. H. Spence, P. Fromme, U. Weierstall, R. Kirian, M. Hunter, R. B. Doak, S. Marchesini, S. P. Hau-Riege, M. Frank, R. L. Shoeman, L. Lomb, S. W. Epp, R. Hartmann, D. Rolles, A. Rudenko, C. Schmidt, L. Foucar, N. Kimmel, P. Holl, B. Rudek, B. Erk, A. Hoemke, C. Reich, D. Pietschner, G. Weidenspointner, L. Strueder, G. Hauser, H. Gorke, J. Ullrich, I. Schlichting, S. Herrmann, G. Schaller, F. Schopper, H. Soltau, K.-U. Kuehnel, R. Andritschke, C.-D. Schroeter, F. Krasniqi, M. Bott, S. Schorb, D. Rupp, M. Adolph, T. Gorkhover, H. Hirsemann, G. Potdevin, H. Graafsma, B. Nilsson, H. N. Chapman and J. Hajdu, Nature, 2011, 470, 78-86.

15 L. Strüder, U. Briel, K. Dennerl, R. Hartmann, E. Kendziorra, N. Meidinger, E. Pfeffermann, C. Reppin, B. Aschenbach, W. Bornemann, H. Brauninger, W. Burkert, M. Elender, M. Freyberg, F. Haberl, H. Hartner, F. Heuschmann, H. Hippmann, E. Kastelic, S. Kemmer, G. Kettenring, W. Kink, N. Krause, S. Muller, A. Oppitz, W. Pietsch, M. Popp, P. Predehl, A. Read, K. H. Stephan, D. Stotter, J. Trumper, P. Holl, J. Kemmer, H. Soltau, R. Stotter, U. Weber, U. Weichert, C. von Zanthier, D. Carathanassis, G. Lutz, R. H. Richter, P. Solc, H. Bottcher, M. Kuster, R. Staubert, A. Abbey, A. Holland, M. Turner, M. Balasini, G. F. Bignami, N. La Palombara, G. Villa, W. Buttler, F. Gianini, R. Laine, D. Lumb and P. Dhez, Astron. Astrophys., 2001, 365, L18-L26.

16 P. J. Keller, A. D. Schmidt, J. Wittbrodt and E. H. K. Stelzer, Science, 2008, 322, 1065-1069.

17 B. Ohnesorge, T. Flohr, S. Schaller, K. Klingenbeck-Regn, C. Becker, U. J. Schopf, R. Bruning and M. F. Reiser, Radiologe, 1999, 39, 923-931.

18 H. Riesemeier, K. Ecker, W. Görner, B. R. Müller, M. Radtke and M. Krumrey, X-Ray Spectrom., 2005, 34, 160-163.

19 K. Byard, Nucl. Instrum. Methods Phys. Res., Sect. A, 1993, 336, 262-268.

20 S. R. Gottesman and E. E. Fenimore, Appl. Opt., 1989, 28, 4344-4352.

21 P. Duvauchelle, G. Peix and D. Babot, Nucl. Instrum. Methods Phys. Res., Sect. B, 1999, 155, 221-228.

22 M. P. Singh, B. S. Sandhu and B. Singh, Nucl. Instrum. Methods Phys. Res., Sect. A, 2007, 580, 50-53.

23 A. Kuczumow, B. Vekemans, O. Schalm, L. Vincze, W. Dorrine, K. Gysels and R. Van Grieken, X-Ray Spectrom., 1999, 28, 282-291.

24 C. Y. Hsu, Biol. Cell, 2004, 96, 529-537.

25 L. Hare, Crit. Rev. Toxicol., 1992, 22, 327-369.

26 M. van der Spiegel, M. Y. Noordam and H. J. van der Fels-Klerx, Compr. Rev. Food Sci. Food Saf., 2013, 12, 662-678. 
27 P. Vogel, Rev. Suisse Zool., 1984, 91.

28 F. E. Brenker, L. Vincze, B. Vekemans, L. Nasdala, T. Stachel, C. Vollmer, M. Kersten, A. Somogyi, F. Adams, W. Joswig and J. W. Harris, Earth Planet. Sci. Lett., 2005, 236, 579-587.

29 N. Zoeger, P. Roschger, J. G. Hofstaetter, C. Jokubonis, G. Pepponi, G. Falkenberg, P. Fratzl, A. Berzlanovich,
W. Osterode, C. Streli and P. Wobrauschek, Osteoarthritis. Cartilage., 2006, 14, 906-913.

30 W. Malzer and B. Kanngiesser, Spectrochim. Acta, Part B, 2005, 60, 1334-1341.

31 F. Doring, A. L. Robisch, C. Eberl, M. Osterhoff, A. Ruhlandt, T. Liese, F. Schlenkrich, S. Hoffmann, M. Bartels, T. Salditt and H. U. Krebs, Opt. Express, 2013, 21, 19311-19323. 